\title{
The Day of the Week Effect on Stock Market Volatility
}

\author{
Hakan Berument and Halil Kiymaz
}

\begin{abstract}
This study tests the presence of the day of the week effect on stock market volatility by using the S\&P 500 market index during the period of January 1973 and October 1997. The findings show that the day of the week effect is present in both volatility and return equations. While the highest and lowest returns are observed on Wednesday and Monday, the highest and the lowest volatility are observed on Friday and Wednesday, respectively. Further investigation of sub-periods reinforces our findings that the volatility pattern across the days of the week is statistically different. (JEL G10, G12,
\end{abstract} C22)

\section{Introduction}

The presence of calendar anomalies has been documented extensively for the last two decades in financial markets. The most common ones are the January Effect and the Day of the Week Effect. The day of the week patterns have been investigated extensively in different markets. Studies (Cross 1973; French 1980; Keim and Stambaugh 1984; Rogalski 1984; Aggarwal and Rivoli 1989) document that the distribution of stock returns varies according to the day of the week. The average return on Monday is significantly less than the average return over the other days of the week. The day of the week regularity is not limited to the U.S. equity market. It is also documented that the day of the week regularity is present in other international equity markets (Jaffe and Westerfield 1985; Solnik and Bousquet 1990; Barone 1990, among others) and other financial markets including the futures market, Treasury bill market, and bond market (Cornell 1985; Dyl and Maberly 1986).

While the focus of the studies above has been the seasonal pattern in mean return, recently many empirical studies have investigated the time series behavior of stock prices in terms of volatility by using variations of the generalized autoregressive conditional heteroskedasticity (GARCH) models (French, Schwert, and Stambaugh 1987; Akgiray 1989; Baillie and DeGennaro 1990;Hamao, Masulis, and Ng 1990; Nelson 1991; Campbell and Hentschel 1992; Glosten, Jagannathan and Runkle 1993). However, none of these studies examine if there is any day of the

\footnotetext{
* Hakan Berument, Bilkent University, Ankara, Turkey; Halil Kiymaz (corresponding author), Department of Finance, SBPA, University of Houston-Clear Lake, Houston, TX 77058, kiymaz@cl.uh.edu. The authors would like to thank anonymous referees, Joachim Zietz (JEF editor), Aslıhan Salih Altay, Kürsat Aydogan, Umur Çelikyay, and Ramazan Gencay for helpful comments.
} 
week variation in volatility. One may expect variations in volatility across days of the week. French and Roll (1986) propose that the variances for the days following an exchange holiday should be larger than other days. Harvey and Huang (1991) observe higher volatility in the interest rates and foreign exchange futures markets during first trading hours on Thursdays and Fridays.

It is important to know whether there are variations in volatility of stock returns by day of the week patterns and whether a high (low) return is associated with a corresponding high (low) return for a given day. Having such knowledge may allow investors to adjust their portfolios by taking into account day of the week variations in volatility. For example, Engle (1993) argues that investors who dislike risk may adjust their portfolios by reducing their investments in those assets whose volatility is expected to increase. Finding certain patterns in volatility may be useful in several ways, including the use of predicted volatility patterns in hedging and speculative purposes and use of predicted volatility in valuation of certain assets specifically stock index options.

The purpose of this study is to investigate day of the week effect in stock market volatility by examining the S\&P 500 stock index during the period of January 1973 and October 1997. Furthermore, the differences in day of the week effect in volatility are examined by dividing the sample period into pre- and post-1987 periods. None of the previous studies have investigated day of the week effect in the stock return volatility framework. The paper contributes to the literature by documenting the presence of the day of the week effect patterns in the conditional variance specification.

\section{Literature Review}

There is an extensive literature on day of the week effect for the stock returns. Among studies investigating the day of the week anomaly for the U.S. market, Cross (1973) studies the returns on the S\&P 500 Index over the period of 1953 and 1970. His findings indicate that the mean return on Friday is higher than the mean return on Monday. Similar results are reported by French (1980), who also studied the S\&P 500 index for the period of 1953-1977. Gibbons and Hess (1981) find negative Monday returns for 30 stocks of Dow Jones Industrial Index. Keim and Stambaugh (1984) further investigate the weekend effect by using longer time periods for various portfolios. Their results confirm the findings of previous studies. Several studies also attempted to explain the Monday effect, among them calendar time hypothesis, which states that Monday returns should be higher than other weekday returns (French 1980), the delay between trading and settlements in stocks (Gibbons and Hess 1981; Lakonishok and Levi 1982), and measurement errors (Gibbons and Hess 1981; Keim and Stambaugh 1984) may be cited. These studies measure Monday return between the closing price on Friday and the closing price on Monday. Rogalski (1984) answers the question of whether prices fall between Friday close and Monday opening or during the day on Monday. He composes daily returns into trading and non-trading day returns and finds that all of the average negative returns from Friday close to Monday close occur during the non-trading hours. Average trading day returns (open to close) are identical for all days.

Day of the week patterns also exist in other U.S. markets. The futures market, the Treasury bill market, and the bond market display a pattern similar to that of the equity market (Cornell 1985; Dyl and Maberly 1986). Day of the week effect is also documented for other stock markets around the world. Among them, Jaffe and Westerfield (1985) investigate the weekend effect in four developed markets, namely Australia, Canada, Japan. and the U.K. The results indicate the existence of weekend effect in all countries studied. Contrary to previous studies of the U.S. market, the lowest mean returns for both Japanese and Australian stock markets were found to be on Tuesday. Solnik and Bousquet (1990) test day of week effect for Paris Bourse, reporting a strong and persistent negative return on Tuesday, which is in line with studies on Australia and Japan. Barone (1990) reports similar results for the Italian Stock Market, with the largest decline 
in stock prices occurring in the first two days of the week and more pronounced on Tuesday. More recently, Agrawal and Tandon (1994), Alexakis and Xanthakis (1995), and Balaban (1995) also show that the distribution of stock returns varies by day of the week for various countries. In sum, day of the week effect in stock returns is a common phenomenon and observed across different countries and different types of markets. However, none of these studies has investigated day of the week effect in stock market volatility.

A set of empirical studies recently has investigated the time series behavior of stock prices in terms of volatility by using variations of GARCH models (French, Schwert, and Stambaugh 1987; Akgiray 1989; Baillie and DeGennaro 1990; Hamao, Masulis, and Ng 1990; Nelson 1991; Campbell and Hentschel 1992; Glosten, Jagannathan, and Runkle 1993). French, Schwert and Stambaugh (1987) examine the relation between stock prices and volatility and report that unexpected stock market returns are negatively related to the unexpected changes in volatility. Campbell and Hentschel (1992) report similar results. They argue that an increase in stock market volatility raises required stock returns, and hence lowers stock prices. Nelson (1991) and Glosten, Jagannathan, and Runkle (1993), on the other hand, report that positive unanticipated returns result in reduction in conditional volatility, whereas negative unanticipated returns result in upward movements in conditional volatility. Baillie and DeGennaro (1990) report no evidence of a relationship between mean returns on a portfolio of stocks and the variance or standard deviation of those returns. These findings are supported by Chan, Karolyi and Stulz (1992), who report a significant foreign influence on the time-varying risk premium for U.S. stocks but no significant relation between the conditional expected excess return on the S\&P 500 and its conditional variance.

More recently, Corhay and Rad (1994) and Theodossiou and Lee (1995) investigated the behavior of stock market volatility and its relationship to expected returns for major European stock markets. Both studies report the existence of significant conditional heteroskedasticity in stock price behavior. No relationship between stock market volatility and expected returns is found. None of these studies, however, has investigated the variation in stock market volatility with respect to day of the week patterns. Finding certain patterns in volatility may be useful in several ways, including the use of predicted volatility pattern in hedging and speculative purposes; use of predicted volatility in valuation of certain assets - specifically stock index options. This paper provides evidence on day of the week effect pattern in stock market volatility.

\section{Methodology}

This study tests the presence of day of the week effect in both the return and volatility equations. The stock return data used in this study consist of logarithmic first difference of the S\&P 500 stock index closing prices. There is a total of 6,409 daily observations ranging from January 3, 1973, to October 20, 1997. ${ }^{1}$

The presence of day of the week effect is documented in the literature extensively for mean return. We also initially estimate day of the week effect in return equation by using Ordinary Least Square method (OLS). We use the following equation:

$$
\text { Return }_{\mathrm{t}}=\mathrm{C}_{\mathrm{M}} \mathrm{D}_{\mathrm{Mt}}+\mathrm{C}_{\mathrm{T}} \mathrm{D}_{\mathrm{Tt}}+\mathrm{C}_{\mathrm{W}} \mathrm{D}_{\mathrm{Wt}}+\mathrm{C}_{\mathrm{H}} \mathrm{D}_{\mathrm{Ht}}+\mathrm{C}_{\mathrm{F}} \mathrm{D}_{\mathrm{Ft}}+\sum_{i=1}^{p} \operatorname{Return}_{\mathrm{t}-\mathrm{i}}+\varepsilon_{\mathrm{t}}
$$

where $\mathrm{D}_{\mathrm{Mt}}, \mathrm{D}_{\mathrm{Tt}}, \mathrm{D}_{\mathrm{Wt}}, \mathrm{D}_{\mathrm{Ht}}$ and $\mathrm{D}_{\mathrm{Ft}}$ are the dummy variables for Monday, Tuesday, Wednesday, Thursday, and Friday, respectively. Moreover, we included the lag values of the return variable to the equation to eliminate the possibility of having autocorrelated errors. The above equation

\footnotetext{
${ }^{1}$ We exclude 10 daily observations from the sample before and after the October 19, 1987, crash.
} 
assumes the existence of a constant variance, which may result in inefficient estimates, if there is a time varying variance. Therefore, we include the changing variance into estimation. Here, we assume that the error term of the return equation has a normal distribution with zero mean and time varying conditional variance of $h_{t}\left(\varepsilon_{\mathrm{t}} \sim \mathrm{N}\left(0, h_{t}\right)\right)$.

Various types of modeling of conditional variances are employed in the literature. Engle (1982) suggests a model that allows the forecast variance of return equation to vary systematically over time. Here the assumption is that conditional variance, $h_{t}$, depends upon the past squared residuals from the Return $n_{t}$ equation, $\left(h_{t}=V_{C}+\sum_{j=1}^{q} V_{j} \varepsilon_{t-j}^{2}\right)$, which is known as Autoregressive Conditional Heteroskedastic Models (ARCH). Bollerslev (1986) then extends the ARCH process by making $h_{t}$ a function of lagged values of $h_{t}$ as well as the lag values of $\varepsilon_{\mathrm{t}}^{2} .\left(h_{t}=V c+\sum_{j=1}^{q} V_{A j}\right.$ $\left.h_{t-j}+\sum_{j=1}^{r} V_{B j} \varepsilon_{t-j}^{2}\right)$. This type of modeling is known as GARCH models. Here this specification requires that $\sum_{j=1}^{q} V_{A j}+\sum_{j=1}^{r} V_{B j}<1$, in order to satisfy the non-explosiveness of the conditional variances and that each of $V_{A}, V_{B}$, and $V_{C}$ is positive in order to satisfy the non-negativity of conditional variances. ${ }^{2}$ Here we model the time varying variance by using a GARCH process.

$$
h_{t}=\mathrm{Vc}+\sum_{j=1}^{q} \mathrm{~V}_{\mathrm{Aj}} h_{t-j}+\sum_{j=1}^{r} \mathrm{~V}_{\mathrm{Bj}} \varepsilon_{t-j}^{2}
$$

where the volatility is measured by conditional variance.

Some of the studies in literature also suggest the inclusion of some weakly exogenous variables into the GARCH specification. Among them, Karolyi (1995) includes the volatility of foreign countries' stock market returns to explain the conditional variance of the home country stock market returns. Moreover, Hsieh (1988) reports the day of the week effect in volatility for the British Pound, Canadian Dollar, Deutsche Mark, Japanese Yen, and Swiss Frank in terms of U.S. dollars. Following these studies, we allow some exogenous variables to affect volatility of the stock market returns. More specifically, we allow the constant term of the conditional variance equation to change for each day of the week. The model becomes as follows:

$$
h_{t}=\mathrm{V}_{\mathrm{M}} \mathrm{D}_{\mathrm{Mt}}+\mathrm{V}_{\mathrm{T}} \mathrm{D}_{\mathrm{Tt}}+\mathrm{V}_{\mathrm{W}} \mathrm{D}_{\mathrm{Wt}}+\mathrm{V}_{\mathrm{H}} \mathrm{D}_{\mathrm{Ht}}+\mathrm{V}_{\mathrm{F}} \mathrm{D}_{\mathrm{Ft}}++\sum_{i=1}^{q} \mathrm{~V}_{\mathrm{Aj}} h_{t-i}+\sum_{i=1}^{r} \mathrm{~V}_{\mathrm{Bj}} \varepsilon_{t-i}^{2}
$$

Equations 1 and 3 and 1 and 2 are estimated jointly by using the Full Information Maximum Likelihood estimation technique in order to test the presence of the day of the week effect in both the return and the volatility equations. ${ }^{3}$

\section{Empirical Results}

Table 1 reports the preliminary statistics (evidence) for the returns for the entire study period as well as the return for each day of the week. The average return for the entire study period is 0.016 percent. The variance of the return is 0.140 , and skewness is -0.024 . The kurtosis is 2.632 , and its difference from 3 is statistically significant at the 5 percent level. The Jarque-Berra normality test (not reported) rejects the normality of returns at the 5 percent level.

\footnotetext{
${ }^{2}$ A number of ARCH specifications are used in the literature. Bollerslev, Chou, and Kroner (1992) offer an extensive survey of these studies in finance literature.

${ }^{3}$ Pagan (1984) argues that using regressors generated by a stochastic model can lead to having biased estimates for parameters' standard errors. Pagan and Ullah (1988) suggest estimating those two equations jointly by using the Full Information Maximum Likelihood method.
} 
When the return of each day is analyzed, the findings indicate that Friday has a mean return of 0.017 percent, while Monday has a mean return of -0.003 percent. The signs of the findings are in line with day of the week effect literature (see Cross 1973; Lakonishok and Levi 1982; Rogalski 1984; Keim and Stambaugh 1984; Harris 1986a, 1986b). On the other hand, the returns for Tuesday and Wednesday are positive and statically significantly different from zero. We observe the highest return on Wednesday (similar pattern is also reported for S\&P 500 by Rogalski 1984 and Jaffe and Westerfield 1985) and the lowest returns on Monday.

TABle 1. SUMMARY StATISTICS FOR DAILy U.S. EQUiTy MARKET RETURNS

\begin{tabular}{lcccccc}
\hline Statistics & All Days & Monday & Tuesday & Wednesday & Thursday & Friday \\
\hline Observations & 6448 & 1290 & 1289 & 1289 & 1290 & 1290 \\
Mean & 0.0160 & -0.0028 & 0.0226 & 0.0317 & 0.0098 & 0.0166 \\
t-stats & $3.43^{* *}$ & -0.24 & $2.14^{*}$ & $3.14^{* *}$ & 0.97 & 1.59 \\
Variance & 0.139 & 0.158 & 0.145 & 0.133 & 0.131 & 0.140 \\
Skewness & -0.024 & $-0.291^{* *}$ & $0.322^{* *}$ & $0.271^{* *}$ & $0.001^{* *}$ & $-0.600^{* *}$ \\
Kurtosis & $2.632^{*}$ & $2.225^{* *}$ & $1.633^{* *}$ & $2.094^{*}$ & 2.744 & $6.043^{* *}$ \\
\hline
\end{tabular}

Notes: The U.S. equity index is Standard and Poor's 500 stock index from January 1973 to October 1997. ${ }^{* *}$ and ${ }^{*}$ indicate significance at the 1 percent and 5 percent levels, respectively.

Table 1 also reports variances, skewness, and kurtosis for each day. Monday has the highest variance of 0.158 , and Wednesday and Thursday have the lowest variances of 0.131 . Skewness for each day is statistically significant at the 1 percent level. Furthermore, the results for excess kurtosis are also statistically significant with the exception of Thursday. ${ }^{4}$ In general, skewness and kurtosis are observed for each day but not for the entire sample. We further perform the Barttlet's test to see whether the constancy of the variances can be rejected. The calculated statistic is 14.47 , while the critical value $\left(\chi_{4}^{2}\right)$ is 13.28 at the 1 percent level of significance. Hence we reject the null hypothesis that the variance is the same across different days.

Table 2 reports the day of the week effects and stock market volatility during the January 1973 and October 1997 periods by using three different models ${ }^{5}$ : Standard OLS, GARCH $(1,1)$, and Modified GARCH $(1,1)$. The first column reports the results from the OLS estimation.

The results of the OLS estimation show that Monday has the lowest return (-0.0046), while Wednesday has the highest return (0.0292). This result is consistent with the previous finding reported in Table 1. Following Cosimano and Jansen (1988), prior to testing the presence of the time varying conditional variance test, we perform the Ljung-Box Q test with both 10 and 1,602 lags. Based on the Ljung-Box Q tests, we reject the null hypothesis of the existence of autocorrelation in data. Then we perform the Lagrange Multiplier Autoregressive Conditional Heteroskedastic test suggested by Engle (1982) using 12 lags. ${ }^{6}$ In order to perform the Lagrange Multiplier test, we regress the squared residuals using the square of the error terms on its first 12 lags and calculate its

\footnotetext{
${ }^{4}$ We test the difference of kurtosis from three.

${ }^{5}$ We exclude 10 observations from both before and after the October 19, 1987 crash and employ a dummy variable for observations following the post- October 1987 period. Furthermore, we used the Final Prediction Error Criteria (FPE) to determine the Autoregressive order. Using FPE has the advantage of having residuals of the return equation that does not have the autocorrelated residuals. Cosimano and Jansen (1988) argue that the presence of the autocorrelation in the residual terms may misleadingly indicate the presence of the ARCH effect. Hence, in the regression analysis, sufficient numbers of lags are included in order to avoid the autocorrelated errors.

${ }^{6} \mathrm{We}$ also try other lag orders and the basic results remain the same.
} 
$R^{2}$ value. The test statistic is calculated as 1528.01 , while the critical value is 21.03 at the 95 percent level of confidence. Hence, we reject the null hypothesis of constant conditional variance.

TABle 2. Day of THE WeEk EFFECTS AND STOCK MARKet Volatility DURING JANUARY 1973 AND OCTOBER 1997 PERIODS

\begin{tabular}{|c|c|c|c|c|}
\hline & & OLS & $\operatorname{GARCH}(1,1)$ & Modified GARCH $(1,1)$ \\
\hline \multicolumn{5}{|l|}{ Return } \\
\hline \multirow[t]{14}{*}{ Equation } & Monday & -0.0046 & 0.0053 & 0.0049 \\
\hline & & (0.0104) & $(0.0091)$ & $(0.0093)$ \\
\hline & Tuesday & $0.0230^{* * *}$ & $0.0174^{* *}$ & $0.0191^{*}$ \\
\hline & & (0.0104) & $(0.0086)$ & $(0.0095)$ \\
\hline & Wednesday & $0.0292^{* *}$ & $0.0276^{* *}$ & $0.0272^{* *}$ \\
\hline & & (0.0104) & $(0.0095)$ & $(0.0087)$ \\
\hline & Thursday & 0.0064 & 0.0124 & 0.0126 \\
\hline & & $(0.0105)$ & $(0.0093)$ & $(0.0087)$ \\
\hline & Friday & $0.0175^{*}$ & $0.0208^{*}$ & $0.0208^{*}$ \\
\hline & & (0.0104) & $(0.0090)$ & $(0.0094)$ \\
\hline & Return $_{t-1}$ & $0.1080^{* * *}$ & $0.0969^{* *}$ & $0.0979^{*}$ \\
\hline & & $(0.0123)$ & $(0.0118)$ & $(0.0118)$ \\
\hline & Dummy & $-2.6786^{* *}$ & -2.6841 & -2.6839 \\
\hline & & $(0.0372)$ & $(8.8216)$ & $(76.1680)$ \\
\hline \multirow{20}{*}{$\begin{array}{l}\text { Volatility } \\
\text { Equation }\end{array}$} & $\mathrm{VC}$ & & $0.0009^{* *}$ & \\
\hline & & & $(0.0001)$ & \\
\hline & VA & & $0.9567^{* *}$ & $0.9566^{* *}$ \\
\hline & & & $(0.0032)$ & $(0.0033)$ \\
\hline & VB & & $0.0369^{* *}$ & $0.0367^{* *}$ \\
\hline & & & $(0.0028)$ & $(0.0028)$ \\
\hline & Monday & & & -0.0020 \\
\hline & & & & $(0.0042)$ \\
\hline & Tuesday & & & 0.0086 \\
\hline & & & & $(0.0046)$ \\
\hline & Wednesday & & & $-0.0170^{* *}$ \\
\hline & & & & $(0.0043)$ \\
\hline & Thursday & & & 0.0024 \\
\hline & & & & $(0.0040)$ \\
\hline & Friday & & & $0.0086^{*}$ \\
\hline & & & & $(0.0038)$ \\
\hline & Log Like. & & 3560.97 & 3568.13 \\
\hline & Q-stats(10) & 17.10 & 5.63 & 5.14 \\
\hline & Q-stats(1602) & 1525.95 & 1579.45 & 1524.57 \\
\hline & LM Test & 1528.01 & & \\
\hline
\end{tabular}

Notes: Standard errors are reported under the corresponding estimated coefficients. ${ }^{* *}$ and ${ }^{*}$ indicate the level of significance at the 1 percent and 5 percent level, respectively. 
Since the findings by using OLS estimation indicate the presence of autoregressive conditional heteroskedasticity components in squared variances, we model the conditional variance of return equation as a GARCH $(1,1)$ process and re-estimate the return equation with the conditional variance equation jointly. ${ }^{7}$

The second column of Table 2 reports the results of GARCH $(1,1)$ specification. In this estimation, we allow the time varying conditional variance to follow GARCH $(1,1)$ specification. The results indicate that the highest return is observed on Wednesday (0.0276) and the lowest return is on Monday (0.0053). The second highest return is on Friday (0.0208), followed by Tuesday (0.0174). The return results on Tuesday, Wednesday, and Friday are statistically significant. The sum of the coefficients of the GARCH equation without a constant term is less than one, and both of them are positive and statistically significant. Hence, we do not have either negative or explosive implied variances as suggested by Bollerslev (1986) for the specification test. On the other hand, since the summation of these two coefficients is close to one, it indicates that the volatility is persistent.

For the standardized residuals (residual is divided by the standard error of the residual), the Ljung-Box Q statistic of 5.63 (for 10 lags) and 1,579.45 (for 1,602) lead the rejection of the first 10 order and 1,602 order serial correlation at the 5 percent level. Clearly, allowing time varying variance in the estimation process provides us more efficient estimates for the return equation that are in line with previous expectations (Enders 1995). This can be easily observed with the lower standard errors for the estimated parameters of the return equation with the exception of the dummy term. ${ }^{8}$ In sum, the second specification of estimation increases the efficiency of the estimates compared to those of the first one.

The estimation results for the third specification are reported in the fourth column of Table 2 . In our preliminary analysis, we rejected the null hypothesis of same variance for each day of the week. Thus, now we allow for time varying conditional variance to detect the existence of the day of the week effect. The third model, Modified GARCH, also reports the estimates of the five dummy terms that are included for each day. It also excludes the constant term to avoid the dummy variable trap for the volatility equation.

When the Modified GARCH $(1,1)$ is estimated, Monday has the lowest rate of return (0.0049), and Wednesday has the highest rate of return (0.0272). Friday has the second highest rate of return (0.0208), followed by Tuesday (0.0191). The estimated returns for Tuesday, Wednesday, and Friday are statistically significant. Additionally, the lowest volatility is observed on Wednesday (-0.0170) and the highest volatility on Friday (0.0086) after controlling the persistence effect with the lag values of the conditional variance and squared lag values of the residual term. For both days of the week, dummy variables in the conditional variance equation are statistically significant. Consistent with the second model, GARCH coefficients for these two parameters are less than one but quite close to one as reported in the former specification; in addition, they are both positive and statistically significant. Both Ljung-Box Q statistics with 10 and 1,602 lags also reject the presence of the autocorrelated residuals for the standardized residuals.

The likelihood ratio test suggests that we can reject the null hypothesis of no day of the week effect for the conditional variance equation. The calculated statistic is 14.33 , while the critical value at the 1 percent level is 13.28 . Hence, we reject the null hypothesis that there is no day of the

\footnotetext{
${ }^{7}$ We also model the conditional variance as $\operatorname{GARCH}(2,1)$ and $\operatorname{GARCH}(1,2)$ processes; the Likelihood Ratio test cannot reject that these extra terms are zero.

${ }^{8}$ When we exclude the dummy variable from the analysis, the sum of VA and VB is greater than one. This suggests the explosiveness of conditional variance. Hence, we keep the dummy variable throughout the analyses.
} 
week effect present for the volatility equation and conclude that the volatility across day of the week is significantly different.

TABLE 3. DAy OF THE WeEk EFFECTS AND STOCK Market Volatility DURING JANUARY 1973 AND OCTOBER 1987 PERIODS

\begin{tabular}{|c|c|c|c|c|}
\hline & & OLS & $\operatorname{GARCH}(1,1)$ & Modified GARCH $(1,1)$ \\
\hline \multicolumn{5}{|l|}{ Return } \\
\hline \multirow[t]{12}{*}{ Equation } & Monday & $-0.0375^{* *}$ & $-0.0294^{*}$ & $-0.0288^{*}$ \\
\hline & & $(0.0139)$ & $(0.0125)$ & $(0.0128)$ \\
\hline & Tuesday & 0.0184 & 0.0161 & 0.0188 \\
\hline & & $(0.0139)$ & $(0.0114)$ & $(0.0134)$ \\
\hline & Wednesday & $0.0294^{*}$ & 0.0230 & 0.0233 \\
\hline & & $(0.0139)$ & $(0.0125)$ & $(0.0126)$ \\
\hline & Thursday & 0.0195 & 0.0213 & 0.0210 \\
\hline & & $(0.0139)$ & $(0.0131)$ & $(0.0120)$ \\
\hline & Friday & 0.0171 & 0.0245 & $0.0263^{*}$ \\
\hline & & $(0.0139)$ & $(0.0135)$ & $(0.0117)$ \\
\hline & Return $_{t-1}$ & $0.1508^{* *}$ & $0.1436^{* *}$ & $0.1480^{* *}$ \\
\hline & & $(0.0159)$ & $(0.0168)$ & $(0.017)$ \\
\hline \multirow{20}{*}{$\begin{array}{l}\text { Volatility } \\
\text { Equation }\end{array}$} & $\mathrm{VC}$ & & $0.0014^{* *}$ & \\
\hline & & & $(0.0004)$ & \\
\hline & VA & & $0.9496^{* *}$ & $0.9474^{* *}$ \\
\hline & & & $(0.0057)$ & $(0.0061)$ \\
\hline & VB & & $0.0413^{* *}$ & $0.0422^{* *}$ \\
\hline & & & $(0.0044)$ & $(0.0046)$ \\
\hline & Monday & & & $0.0181^{*}$ \\
\hline & & & & $(0.0070)$ \\
\hline & Tuesday & & & $0.0209^{*}$ \\
\hline & & & & $(0.0079)$ \\
\hline & Wednesday & & & $-0.0172^{*}$ \\
\hline & & & & $(0.0075)$ \\
\hline & Thursday & & & -0.0098 \\
\hline & & & & $(0.0063)$ \\
\hline & Friday & & & -0.0084 \\
\hline & & & & $(0.0060)$ \\
\hline & Log Like. & & 1916.58 & 1927.96 \\
\hline & Q-stats(10) & 10.14 & 8.22 & 11.39 \\
\hline & Q-stats(962) & 872.13 & 857.76 & 874.96 \\
\hline & LM Test & 1046.3 & & \\
\hline
\end{tabular}

Notes: Standard errors are reported under the corresponding estimated coefficients ${ }^{* *}$ and ${ }^{*}$ indicate the level of significance at the 1 percent and 5 percent level, respectively. 
TABLE 4. DAY OF THE WeEk EFFECTS AND STOCK MARKET VOLATILITY DURING OCTOBER 1987 AND OCTOBER 1997 PERIODS

\begin{tabular}{|c|c|c|c|c|}
\hline & & OLS & $\operatorname{GARCH}(1,1)$ & Modified GARCH $(1,1)$ \\
\hline \multicolumn{5}{|l|}{ Return } \\
\hline \multirow[t]{14}{*}{ Equation } & \multirow[t]{2}{*}{ Monday } & $0.0437^{* *}$ & $0.0422^{* *}$ & $0.0419^{* *}$ \\
\hline & & $(0.0151)$ & $(0.0131)$ & $(0.0133)$ \\
\hline & \multirow[t]{2}{*}{ Tuesday } & $0.0352^{*}$ & 0.0223 & 0.0236 \\
\hline & & $(0.0151)$ & $(0.0130)$ & $(0.0135)$ \\
\hline & \multirow[t]{2}{*}{ Wednesday } & $0.0311^{*}$ & $0.0335^{*}$ & $0.0345^{* *}$ \\
\hline & & $(0.0151)$ & $(0.0145)$ & $(0.0116)$ \\
\hline & \multirow[t]{2}{*}{ Thursday } & -0.0125 & 0.0050 & 0.0050 \\
\hline & & $(0.0151)$ & $(0.0129)$ & $(0.0127)$ \\
\hline & \multirow[t]{2}{*}{ Friday } & 0.0159 & 0.0140 & 0.0167 \\
\hline & & $(0.0151)$ & $(0.0121)$ & $(0.0146)$ \\
\hline & \multirow[t]{2}{*}{ Return $_{t-1}$} & 0.0278 & 0.0300 & 0.0294 \\
\hline & & $(0.0194)$ & $(0.0166)$ & $(0.0174)$ \\
\hline & \multirow{2}{*}{ Dummy } & $-2.6926^{* *}$ & -2.6903 & -2.6936 \\
\hline & & $(0.3457)$ & $(30.3340)$ & $(6886.72)$ \\
\hline \multirow{20}{*}{$\begin{array}{l}\text { Volatility } \\
\text { Equation }\end{array}$} & \multirow{2}{*}{\multicolumn{2}{|c|}{$\mathrm{VC}$}} & $0.0007^{* *}$ & \\
\hline & & & 0.0001 & \\
\hline & \multirow{2}{*}{\multicolumn{2}{|c|}{ VA }} & $0.9630^{* *}$ & $0.9577^{* *}$ \\
\hline & & & $(0.0038)$ & $(0.0046)$ \\
\hline & \multirow[t]{2}{*}{ VB } & & $0.0312^{* *}$ & $0.0350^{* *}$ \\
\hline & & & $(0.0034)$ & $(0.0040)$ \\
\hline & \multirow[t]{2}{*}{ Monday } & & & -0.0100 \\
\hline & & & & $(0.0054)$ \\
\hline & \multirow[t]{2}{*}{ Tuesday } & & & 0.0012 \\
\hline & & & & $(0.0053)$ \\
\hline & \multirow[t]{2}{*}{ Wednesday } & & & $-0.0157^{* *}$ \\
\hline & & & & $(0.0043)$ \\
\hline & \multirow[t]{2}{*}{ Thursday } & & & $0.0137^{*}$ \\
\hline & & & & $(0.0052)$ \\
\hline & \multirow{2}{*}{ Friday } & & & $0.0146^{*}$ \\
\hline & & & & $(0.0054)$ \\
\hline & Log Like. & & 1660.75 & 1669.47 \\
\hline & Q-stats(10) & 18.36 & 18.47 & 18.63 \\
\hline & Q-stats $(650)$ & 683.21 & 682.38 & 683.03 \\
\hline & LM Test & 478.69 & & \\
\hline
\end{tabular}

Notes: Standard errors are reported under the corresponding estimated coefficients. ${ }^{* *}$ and ${ }^{*}$ indicate the level of significance at the 1 percent and 5 percent level, respectively.

Tables 3 and 4 report the results of sub-period analysis for the pre- and post-October 1987 periods. The purpose of sub-period analysis is to determine whether day of the week effect is 
persistent over time. Clearly during the study period (over 25 years) there have been significant changes in the microstructure and efficiency of markets.

The findings show that day of the week effect is present in stock market volatility in both the pre- and post-crisis periods (the likelihood ratio tests 22.76 and 17.43 both are greater than the $\chi_{5}^{2}$ value -11.1 at the 5 percent level of significance). In both cases Wednesday has the lowest day of the week effect in volatility. However, while the highest volatility is observed on Tuesday during the pre-1987 period, it is observed on Friday during the post-1987 period. It seems that the pattern has changed over the period. Nevertheless in both cases we can reject the null hypothesis that there was no difference in volatility across different days of the week.

A possible reason for the highest uncertainty on Friday might be the fact that there is a tendency for bad news to be released over the weekend. Since investors cannot respond to bad or good news released on the weekend, they may take the weekend expectations into account on Friday. Moreover, Harvey and Huang (1991) report higher volatility in the interest rate and foreign exchange futures markets during the first hours of trading on Thursday and Friday compared to any other one-hour period during the week. They hypothesize that their finding is the result of many economic news releases on Thursday and Friday. Ederington and Lee (1993) further support these results. On the other hand, the lowest volatility on Wednesday might be explained by the following. Wednesday, in the middle of the week, naturally provides the highest number of trading days before and after any transaction. On Wednesday, investors have information sets of the last two days and forecasted for the next two days and more time to react the information.

\section{Summary and Conclusions}

This paper tests the presence of day of the week effect in stock market volatility in addition to returns during the January 1973 and October 1997 periods by using the S\&P 500 Stock Index. Three different models are employed. The first model, which assumes the constancy of the residual term's variance, is OLS. The findings based on this model indicate that day of the week effect is present in the return equation. The highest return is observed on Wednesday, while the lowest return is observed on Monday. These findings are in line with previous studies using the S\&P 500 Index. In the second model, we allow volatility to change over time. Although this model provides more efficient estimates of parameters (lower standard errors of the estimates), the findings are similar to those of the first model. Specifically, the lowest return is observed on Monday, while the highest return is observed on Wednesday. Furthermore, a strong and persistent effect on volatility is detected. Finally, the third model employed is the Modified-GARCH, in which the explanatory power of the variance equation has been increased by incorporating day of the week effect into the GARCH specification. The findings show that the day of the week effect is present in both volatility and the return equation. While the highest and lowest returns are observed on Wednesday and Monday, the highest and the lowest volatility are observed on Friday and Wednesday, respectively. All of these findings are statistically significant. The highest volatility on Friday may be a result of several macroeconomic news releases taking place on Thursday and Friday.

We further repeat our analysis to investigate the day of the week effect in stock market volatility in sub-periods. The results from the pre- and post-1987 periods do reinforce our findings that the volatility patterns across the days of the week are statistically different from each other. In summary, we detect the day of the week effect on both return equation and the volatility (conditional variance) equations. Finding certain patterns in volatility may be useful in several ways, including the use of predicted volatility patterns in hedging and speculative purposes and use of predicted volatility in valuation of certain assets-specifically stock index options. 
Furthermore, investors may adjust their portfolios by reducing their commitments to assets whose volatility is expected to increase and vice versa.

\section{References}

Agrawal, A., and K. Tandon. 1994. "Anomalies or Illusions? Evidence from Stock Markets in Eighteen Countries." Journal of International Money and Finance 13: 83-106.

Aggarwal, R., and P. Rivoli. 1989. "Seasonal and Day-of-the Week Effects in Four Emerging Stock Markets." Financial Review 24: 541-550.

Akgiray, V. 1989. "Conditional Heteroscedasticity in Time Series of Stock Returns: Evidence and Forecast." Journal of Business 62: 55-80.

Alexakis, P., and M. Xanthakis. 1995. "Day of the Week Effect on the Greek Stock Market." Applied Financial Economics 5: 43-50.

Baillie, R. T., and R. P. DeGennaro. 1990. "Stock Returns and Volatility." Journal of Financial and Quantitative Analysis 25: 203-214.

Balaban, E. 1995. "Day of the Week Effects: New Evidence from an Emerging Market." Applied Economics Letters 2: 139-143.

Barone, E. 1990. "The Italian Stock Market: Efficiency and Calendar Anomalies." Journal of Banking and Finance 14: 483-510.

Bollerslev, T. 1986. "Generalized Autoregressive Conditional Heteroscedasticity." Journal of Econometrics 31: 307-327.

Bollerslev, T., R. Chou, and K. Kroner. 1991. "ARCH Modeling in Finance: A Review of the Theory and Empirical Evidence." Journal of Econometrics 52: 5-59.

Campbell, J. Y., and L. Hentschel. 1992. "No News is Good News: An Asymmetric Model of Changing Volatility in Stock Returns." Journal of Financial Economics 31: 281-318.

Chan, K. C., G. A. Karolyi, and R. M. Stulz. 1991. "Global Financial Markets and the Risk Premium on U.S. Equity." Journal of Financial Economics 32: 137-167.

Corhay, A., and A. T. Rad. 1994. "Statistical Properties of Daily Returns: Evidence from European Stock Markets." Journal of Business Finance and Accounting 21: 271-282.

Cornell, B. 1985. "The Weekly Patterns in Stock Returns Cash versus Futures: A Note." Journal of Finance 40: 583-88.

Cosimano, T. F., and D. W. Jansen. 1988. "Estimates of the Variance of U.S. Inflation Based upon ARCH Model." Journal of Money Credit and Banking 20: 409-421.

Cross, F. 1973. "The Behavior of Stock Prices on Fridays and Mondays." Financial Analysts Journal 29: 67-69.

Dyl, E., and E. Maberly. 1986. "The Daily Distribution of Changes in the Price of Stock Futures." Journal of Futures Markets 6: 513-521.

Ederington, L. H., and J. H. Lee. 1993. "How Markets Process Information: News Releases and Volatility." Journal of Finance 48: 1161-1191.

Enders, W. 1995. Applied Econometric Time Series. New York: John Wiley \& Sons, Inc. 
Engle, R. 1982. "Autoregressive Conditional Heteroscedasticity with Estimates of the Variance of United Kingdom Inflation.” Econometrica 50: 987-1007.

Engle, R. 1993.“Statistical Models for Financial Volatility.” Financial Analysts Journal 49: 72-78.

French, K. R. 1980. "Stock Returns and The Weekend Effect." Journal of Financial Economics 8: 55-69.

French, K. R., and R. Roll. 1986. "Stock Return Variances: The Arrival of Information of the Reaction of Traders." Journal of Financial Economics 17: 5-26.

French, K. R., G. W. Schwert, and R. F. Stambaugh. 1987. "Expected Stock Returns and Volatility." Journal of Financial Economics 19: 3-29.

Gibbons, M., and P. Hess. 1981. "Day of the Week Effects and Asset Returns." Journal of Business 54: 579-596.

Glosten, L. R., R. Jagannathan, and D. E. Runkle. 1993. "On the Relation between the Expected Value and the Volatility of the Nominal Excess Returns on Stocks." Journal of Finance 48: 1779-1801.

Hamao, Y., R. Masulis, and V. Ng. 1990. "Correlations in Price Changes and Volatility across International Stock Markets." Review of Financial Studies 3: 281-308.

Harris, L. 1986a. "Transaction Data Study of Weekly and Internal Patterns in Stock Returns." Journal of Financial Economics 16: 99-117.

Harris, L. 1986b. "How to Profit from Interdaily Stock Returns." Journal of Portfolio Management 12: 61-64.

Harvey, C., and R. Huang. 1991. "Volatility in Foreign Exchange Futures Markets." Review of Financial Studies 4: 543-570.

Hoffman, D. 1987. "Two-Step Generalized Least Squares Estimators in Multi-equation Generated Regressor Models." Review of Economics and Statistics 69: 336-46.

Hsieh, D. A. 1988. "The Statistical Properties of Daily Foreign Exchange Rates: 1974-1983." Journal of International Economics 24: 129-145.

Jaffe, J., and R. Westerfield. 1985. "The Weekend Effect in Common Stock Returns: The International Evidence." Journal of Finance 40: 433-454.

Karolyi, A. 1995. "A Multivariate GARCH Model of International Transmission of Stock Returns and Volatility: The Case of the United States and Canada." Journal of Business and Statistics 13: $11-25$.

Keim, D. B., and F. Stambaugh. 1984. "A Further Investigation of Weekend Effects in Stock Returns.” Journal of Finance 39: 819-840.

Lakonishok, J., and M. Levi. 1982. "Weekend Effects on Stock Returns: A Note." Journal of Finance 37: 883-889.

Nelson, D. B. 1991. "Conditional Heteroskedasticity in Asset Returns: A New Approach." Econometrica 59: 347-370.

Pagan, A. 1984. "Econometrics Issues in the Analysis of Regressions with Generated Regressors." International Economic Review 25: 221-47. 
Pagan, A., and A. Ullah. 1988. "The Econometric Analysis of Models with Risk Term.” Journal of Applied Econometrics 3: 87-105.

Pena, J. I. 1995. "Daily Seasonalities and Stock Market Reforms in Spain.” Applied Financial Economics 5: 419-423.

Rogalski, R. J. 1984. "New Findings Regarding Day-of-the-Week Returns over Trading and NonTrading Periods: A Note." Journal of Finance 35: 1603-1614.

Solnik, B., and L. Bousquet. 1990. "Day-of-the-Week Effect on the Paris Bourse." Journal of Banking and Finance 14: 461-468.

Theodossiou, P., and U. Lee. 1995. "Relationship Between Volatility and Expected Returns Across International Stock Markets." Journal of Business Finance and Accounting 22: 289300 . 